\title{
Surface functionalization of carbon fabric towards high-performance epoxy composites via enhanced fiber-matrix interfacial strength and intergrowth charring behavior
}

\author{
L. Zhang ${ }^{1,2}, Y . O u^{1,2}$, D. $-Y$. Wang $^{1 *}$
}

${ }^{1}$ IMDEA Materials Institute, Calle Eric Kandel, 2, 28906 Getafe, Madrid, Spain

${ }^{2}$ E.T.S. de Ingenieros de Caminos, Universidad Politécnica de Madrid, Calle Profesor Aranguren 3, 28040 Madrid, Spain

Received 18 September 2020; accepted in revised form 20 November 2020

\begin{abstract}
The development of carbon fabric reinforced epoxy (CF/EP) composites with excellent mechanical properties and high flame retardancy is desired in both scientific and industrial communities. In this work, the phosphorus-containing flame retardant 9,10-dihydro-9-oxa-10-phosphaphenanthrene 10-oxide (DOPO) based amine functional silane coupling agent was coated on carbon fabric, aiming to promote the interfacial charring behavior, and at the same time, improve the fiber-matrix interfacial strength. With only a small proportion of the hybrid $\mathrm{Si} / \mathrm{N} / \mathrm{P}$ coating on the fiber surface, the resultant composite laminate showed a 26 and 31\% reduction in peak heat release rate and smoke production rate, respectively. Under the combustion, the surface grafted phosphorus compounds effectively promoted the interfacial charring behavior of EP composites. An integrated and dense char layer composed of carbon fabric with sealed gaps was formed to protect the underlying polymer materials in the condensed phase. In addition, the fiber push-in test clearly revealed an increased fibermatrix interfacial strength (35\%) due to the existence of amine groups on the fiber surface. The provided Si/N/P hybrid surface functionalization strategy proved to be an effective approach to prepare high-performance flame retardant $\mathrm{CF} / \mathrm{EP}$ composite.
\end{abstract}

Keywords: polymer composites, surface functionalization, flame retardancy, interfacial strength

\section{Introduction}

Carbon fiber has been widely used in developing high-performance epoxy (EP) composites in fields such as automotive and aerospace due to its low-density, high specific strength, and excellent resistance to chemical attack [1-3]. However, the high flammability of EP greatly restricts its applications in some fields with high fire safety requirements. Though carbon fabric (CF) is inherently non-flammable, it does not show a good barrier effect to shield the underlying polymer materials under combustion. Therefore, imparting flame resistance to EP and its composites is an important and active topic in both scientific and industrial communities [4-6].

Generally, flame retardant additives are directly mixed into epoxy resin before the molding process of $\mathrm{CF} / \mathrm{EP}$ composites [7-9]. The flame retardant modified EP matrix showed a high flame retardancy, which in turn improved the fire safety of resultant fiber-reinforced composites. However, some drawbacks are inherent and inevitable in this bulk flame retardant method. On the one hand, high loading of additives is usually needed to endow the materials with a good flame retardancy, which may cause serious deterioration of

${ }^{*}$ Corresponding author, e-mail: deyi.wang@imdea.org

(C) BME-PT 
other critical material properties, especially the mechanical and thermal properties $[10,11]$. On the other hand, during the resin transfer molding process, some flame retardant particles can be filtered by the reinforcing fabrics, resulting in a non-uniform dispersion of additives, as well as the declined flame retardant efficiency and mechanical properties. In our previous study [10], with the addition of $8 \mathrm{wt} \%$ phenylphosphonic amide flame retardant in EP matrix, the resultant modified CF/EP composite showed a high LOI value of $43 \%$. However, the flame retardant showed a negative effect in decreasing the peak heat release rate in the cone calorimeter test. Besides, the interfacial strength between EP matrix and carbon fiber was decreased due to the impact of the flame retardant on cross-linking density and polarity of the matrix.

Alternatively, the surface flame retardant functionalization of carbon (or glass) fiber provides an ideal solution to avoid the aforementioned drawbacks [12-14]. With a uniform dispersion of flame retardant on the fiber surface, it is expected the composites can reach a high flame retardancy, and at the same time, maintain good mechanical properties. Liu and coworkers have performed some pioneering works in developing flame retardant fiber-reinforced composites via the interfacial carbonation strategy $[12,15,16]$. Under the combustion of thermoplastic polymers, the grafted flame retardant promoted the formation of rough char residues on the initially smooth and high-energy fiber surface. The intergrowth char layer effectively delayed the adsorption, wetting, spread, and flow of polymer melt on the glass fiber, thus greatly weakening the wicking action of glass fiber [16]. Recently, Wang and coworkers modified carbon fiber via soaking $\mathrm{CF}$ in an aqueous solution of polyelectrolyte complexes consisting of polyethyleneimine and ammonium polyphosphate at room temperature [13]. The phosphorus-containing coating on $\mathrm{CF}$ surfaces endowed the $\mathrm{CF} / \mathrm{EP}$ composite a high LOI value of 43 and a $47 \%$ reduction of the peak heat release rate in the cone calorimeter test. Moreover, enhanced mechanical properties and increased glass transition temperature were observed for the composites with surface-modified carbon fibers.

Due to the large volume fraction of micrometer fibers, a very large interface area exists in the composite materials. Hence, the material performances are significantly controlled by the interface properties, and in particular, the interface strength plays a dominant role in the mechanical properties of fiber-reinforced composites [17-19]. However, there is a lack of experimental data showing the exact value of this important interface property [20]. In our recent studies, the DOPO-based amine functional silane coupling agent has proved to be effective to improve the charring behavior and filler-matrix adhesion in hollow glass microsphere/EP composites [21]. Compared to powder-like hollow glass microsphere, the continuous carbon fabric composed of well-aligned graphite fibers not only provides superior reinforcement for the matrix but also owes the potential as a perfect grid for the construction of an integrated and dense char layer. Hence, in this work, the DOPO-based amine functional silane coupling agent was adopted to coat carbon fabric in EP composites. Furthermore, the fiber push-in technique was used to quantitatively evaluate the influence of surface functionalization on the fiber-matrix interfacial strength.

\section{Experimental}

\subsection{Materials}

The following chemicals were purchased from Sigma-Aldrich, including acetic acid, dichloromethane $\left(\mathrm{CH}_{2} \mathrm{Cl}_{2}\right)$, carbon tetrachloride $\left(\mathrm{CCl}_{4}\right)$, triethylamine $\left(\mathrm{Et}_{3} \mathrm{~N}\right)$, [3-(2-aminoethylamino)propyl] trimethoxysilane (Z-6020, Dow Corning ${ }^{\circledR}$ product). Ethanol was supplied by ITW Reagents, PanReac AppliChem. 9,10-dihydro-9-oxa-10-phosphaphenanthrene 10-oxide (DOPO) was supplied by Tokyo Chemical Industry. The high-temperature, epoxybased laminating system composed of two components (epoxy resin MP and hardener MP) and carbon fabric were provided by R\&G Faserverbundwerkstoffe GmbH Composite Technology. Bisphenol A diglycidyl ether, 1,4-bis(2,3 epoxypropoxy)butane and butanedioldiglycidyl ether are the main constituents of the epoxy resin MP (number average molecular weight less than 700). Diethylmethylbenzenediamine, bisphenol A and p-toluenesulphonic acid are the main constituents of the hardener MP. The plain weave carbon fabric $\left(0 / 90^{\circ}\right)$ owes an area weight of $200 \pm 5 \mathrm{~g} / \mathrm{m}^{2}$. Deionized water was obtained from the water purification system in our laboratory.

\subsection{Preparation of CF@Z6020-DOPO}

The carbon fabric was cut into sheets with a size of $12 \times 120 \mathrm{~cm}^{2}$, followed by the heat treatment under 
$400^{\circ} \mathrm{C}$ for $20 \mathrm{~min}$ to remove the original sizing agent. The DOPO-based amine functional silane coupling agent (Z6020-DOPO) was prepared via the AthertonTodd reaction [21-23]. In short, DOPO (23.1 mmol), Z-6020 (23.1 mmol), and $\mathrm{Et}_{3} \mathrm{~N}(23.1 \mathrm{mmol})$ were added into $20 \mathrm{ml}$ of dichloromethane under an ice bath. After that, $\mathrm{CCl}_{4}(23.1 \mathrm{mmol})$ was added dropwise to the above mixture. Then the reaction was continued under stirring at a room temperature for $12 \mathrm{~h}$. After evaporation, the obtained mixture containing Z6020-DOPO was dissolved in $2000 \mathrm{ml}$ ethanol-5\% water solution with a $\mathrm{PH}$ adjusted to 4.5 by acetic acid. The carbon fabric sheet was rolled on the supporting instrument and immersed in the silane containing solvent under stirring for $60 \mathrm{~min}$. After that, the carbon fabric was thoroughly washed with ethanol and water to remove unreacted DOPO molecular and other impurities. Finally, the surface-modified carbon fabric (CF@Z6020-DOPO) was obtained after dry at $110^{\circ} \mathrm{C}$ for $20 \mathrm{~min}$ and then in an oven at $70^{\circ} \mathrm{C}$ overnight. The surface functionalization procedure is well depicted in Figure 1. The weight percentage of flame retardant on CF@Z6020-DOPO was calculated to be $3.6 \mathrm{wt} \%$ according to the statistical data of fabric weights before and after functionalization.

\subsection{Preparation of $\mathbf{C F} / \mathbf{E P}$ composites}

The preparation of $\mathrm{CF} / \mathrm{EP}$ composite laminate is illustrated below [24]: Firstly, the epoxy resin MP $(200 \mathrm{~g})$ and hardener MP $(80 \mathrm{~g})$ were well mixed in the glass beaker at room temperature. Subsequently, 8 pieces of carbon fabric with a size of $12 \times 22 \mathrm{~cm}^{2}$ were stacked together and sealed in the vacuum bag on a flat aluminum plate. The vacuum-assisted resin transfer molding (VARTM) process was used to prepare the CF/EP composites, as illustrated in Figure 2. The prepared composite laminate, along with the vacuum bag, was placed in an oven for $8 \mathrm{~h}$ at $100^{\circ} \mathrm{C}$ before demolding. After that, the post-curing schedule according to the provider was performed: Start at $100^{\circ} \mathrm{C}$ and heat up with a temperature increase of $10^{\circ} \mathrm{C} / \mathrm{h}$ to $200^{\circ} \mathrm{C}$, hold it for $12 \mathrm{~h}$ and slowly cool down to room temperature.CF@Z6020-DOPO/EP was prepared in the same procedure. The control sample, $\mathrm{CF} / \mathrm{DOPO} / \mathrm{EP}$, was prepared by directly adding $4.5 \mathrm{wt} \%$ DOPO in the resin. To improve the dispersion of DOPO in epoxy resin, a three-roll mill was used before the VARTM process. The specimens for fire testing and DMA were cut from the laminate according to the required sizes. It is worth noting that all the testing specimens had the same thickness of

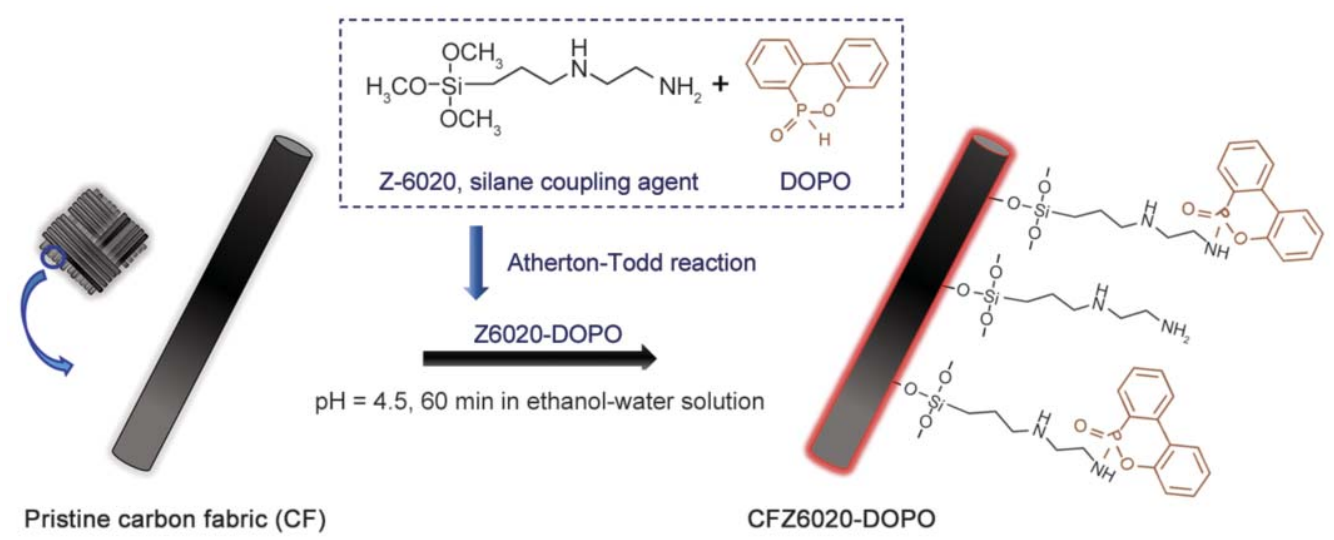

Figure 1. Schematic illustration of the strategy to functionalize carbon fabric.

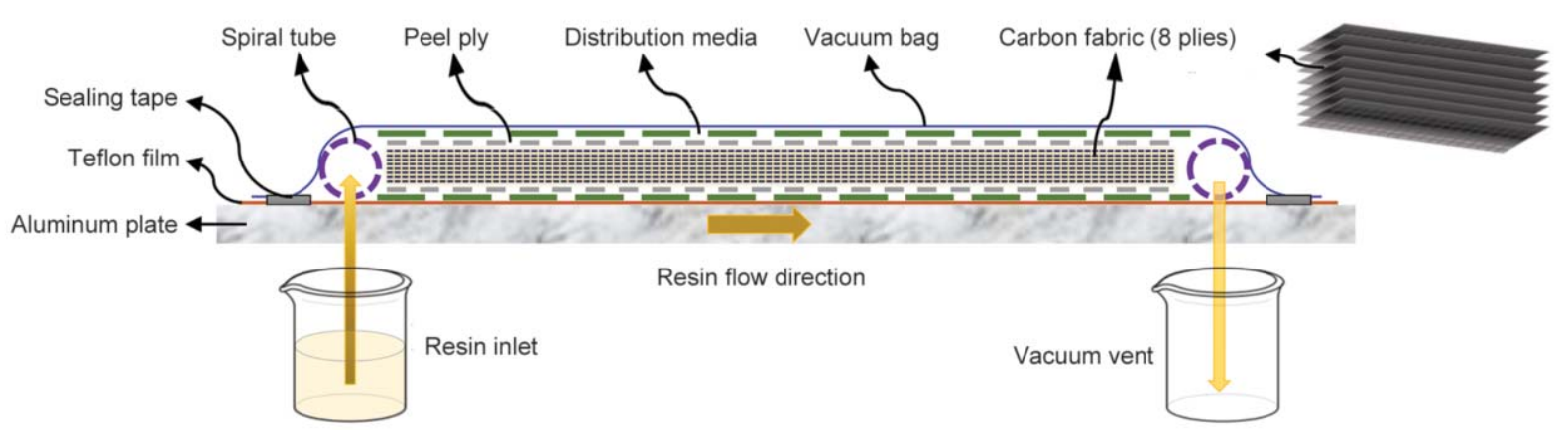

Figure 2. Schematic illustration of the vacuum assisted resin transfer molding (VARTM) process for the preparation of CF/EP composites. 
$2.3 \pm 0.1 \mathrm{~mm}$. According to the calculated weight of carbon fabrics (with an area weight of $200 \mathrm{~g} / \mathrm{m}^{2}$ ) and the measured weight of composite bars, the CF content in the composites was calculated to be around $55 \pm 2 \mathrm{wt} \%$.

\subsection{Characterization}

The morphologies of functionalized carbon fabric, char residues were observed by scanning electron microscopy (SEM) on FEI Helios NanoLab 600i microscope coupled with energy dispersive X-ray spectrometry (EDX). ATR-FTIR was conducted on the FTIR spectrometer (Nicolet iS50) equipped with an Attenuated Total Reflection (ATR) element. Thermogravimetric analysis (TGA) was conducted on the thermal gravimetric analyzer (TA Q50), under a heating rate of $10^{\circ} \mathrm{C} / \mathrm{min}$ in a nitrogen atmosphere. X-ray photoelectron spectroscopy (XPS) was conducted on VG ESCALAB MK II spectrometer with Mg K Alpha excitation source.

Limiting oxygen index (LOI) values of polymer composites were measured by FTT (Fire Testing Technology) instrument following ASTM D2863. UL-94 vertical burning tests were performed according to ASTM D3801. Cone calorimeter tests (CCT) were performed according to ISO 5660-1 under a heat flux of $50 \mathrm{~kW} / \mathrm{m}^{2}$; the thickness of sample was $2.3 \mathrm{~mm}$, and at least two samples were tested for each group. Dynamic mechanical analysis (DMA) was operated on TA Instruments Q800, from room temperature to $230^{\circ} \mathrm{C}$ with a heating rate of $3{ }^{\circ} \mathrm{C} / \mathrm{min}$. The indentation test was carried out on the Hysitron TI950 Triboindenter with a $5 \mu \mathrm{m}$ diameter flat-punch

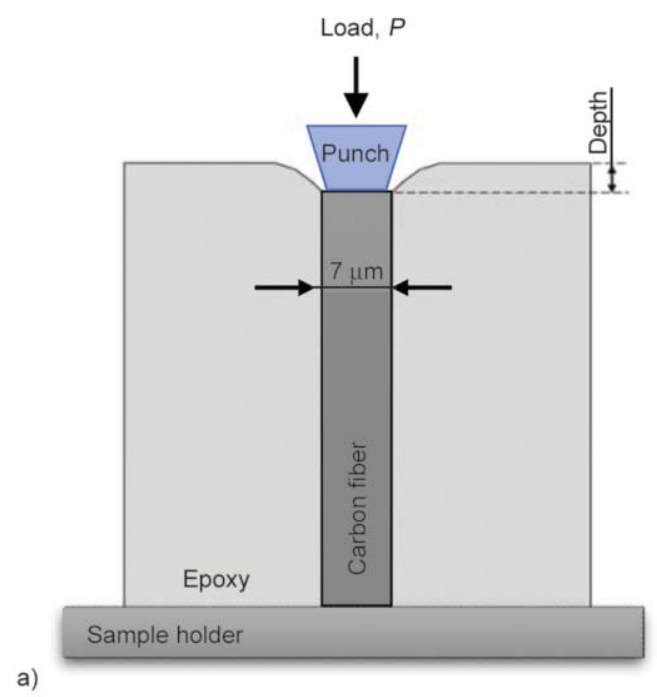

indenter. Specimen surface was prepared by mechanical grinding using silicon carbide papers and polishing on the velvet cloths (NAP Struers). The fiber push-in test was carried out by loading on the center of carbon fiber with a flat-punch indenter until a certain displacement $(1.5 \mu \mathrm{m})$. A constant loading rate of $100 \mathrm{~nm} / \mathrm{s}$ was used in the indentation test. At least five points were tested for each specimen. The interfacial strength $(\tau)$ was calculated according to the shear lag model, see Equation (1) [25-27]:

$\tau=\frac{S_{0} P_{0}}{2 \pi^{2} r^{3} E_{1}^{\mathrm{f}}}$

where $E_{1}^{\mathrm{f}}$ stands for the longitudinal elastic fiber modulus, $r$ is the radius of carbon fiber, $S_{0}$ is the stiffness of the elastic region in the load-depth curve, and $P_{0}$ is the critical load at the onset of nonlinearity, also called the critical point, $P_{\mathrm{c}}$. The test method and the obtained representative load-depth curve was depicted in Figure 3.

\section{Results and discussion}

\subsection{Characterization of functionalized carbon fabric}

The SEM images of raw and functionalized CF are displayed in Figure 4. The raw carbon fabric owned a smooth fiber surface (Figure 4a). After functionalization, CF@Z6020-DOPO showed a rough surface with additional flame retardant layers (Figure 4b, 4c). The element mapping images (Figure 4d) clearly showed the existence of Si, N, P elements alongside the carbon fibers, which were mainly assigned to the surface grafted DOPO-based amine functional silane

Figure 3. (a) Schematic of the fiber push-in test and (b) representative load-depth curve in carbon fabric reinforced EP composite. 


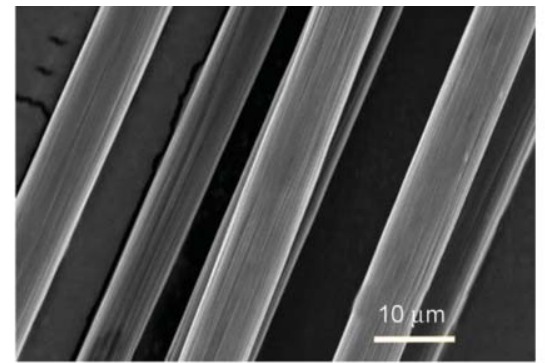

a)

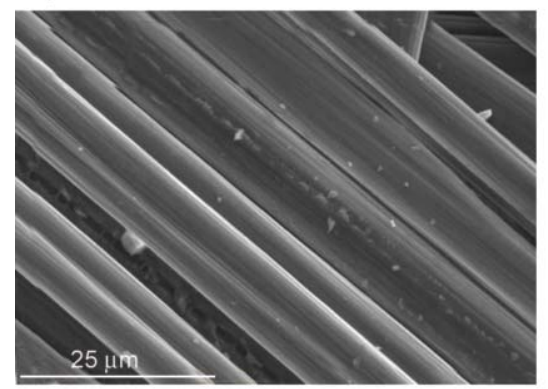

d-i)

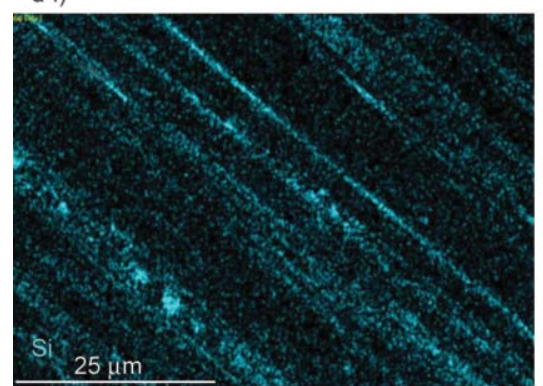

d-iv)

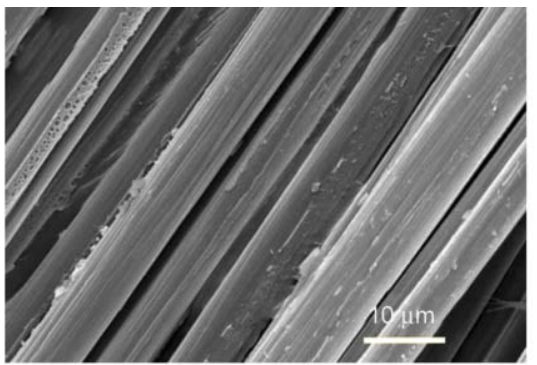

b)

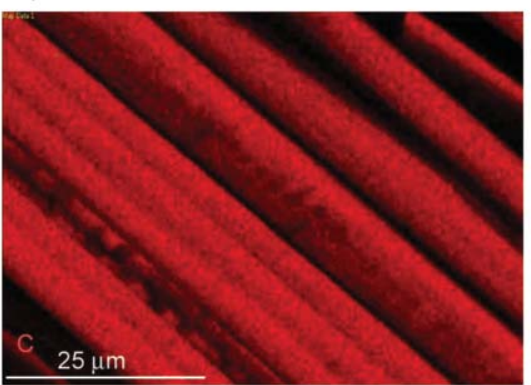

d-ii)

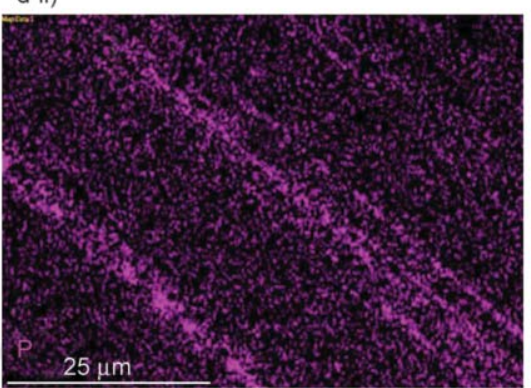

$d-v)$

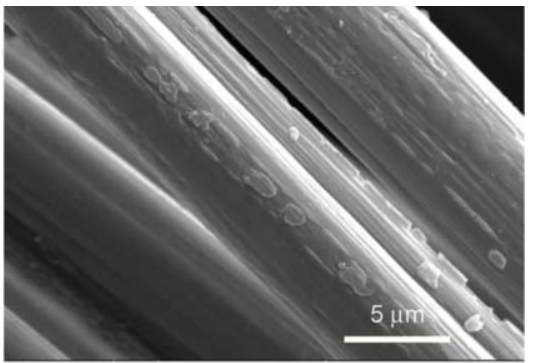

c)

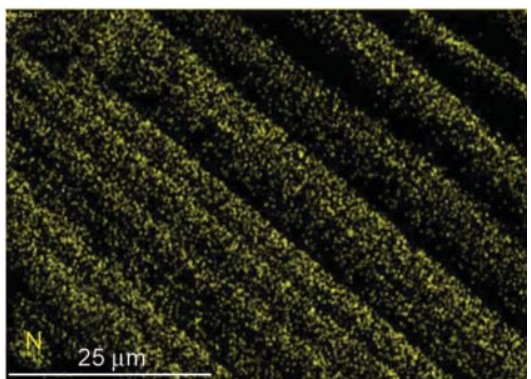

d-iii)

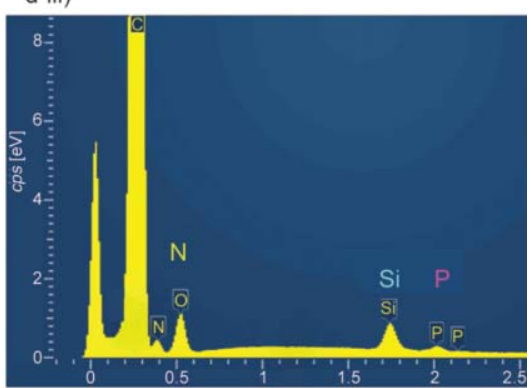

e)

Figure 4. SEM images of (a) raw CF, (b, c) CF@Z6020-DOPO at different resolutions, (d) element mappings and (e) EDX spectra of CF@Z6020-DOPO.

coupling. The EDX spectra in Figure 4e further proved the coexistence of flame retardant elements (Si, N, P) in CF@Z6020-DOPO.

The surface chemical changes were further studied by TGA, FTIR, and XPS measurements, as shown in Figure 5. The raw $\mathrm{CF}$ was thermally stable during 200-500 ${ }^{\circ} \mathrm{C}$ under nitrogen atmospheres. CF@Z6020DOPO showed a mass loss (around $1.2 \mathrm{wt} \%$ ) during $250-450{ }^{\circ} \mathrm{C}$, which was mainly due to the decomposition of organic groups in the synthesized DOPObased silane coupling agent. As seen from Figure 6, the weight loss of Z6020-DOPO during $250-450^{\circ} \mathrm{C}$ was $36.5 \mathrm{wt} \%$. The Z6020-DOPO was collected from the beaker surface after modification of carbon fabric and dried at $80^{\circ} \mathrm{C}$ for $6 \mathrm{~h}$ before the TGA test. Thus the mass loss of $1.2 \mathrm{wt} \%$ in Figure $5 \mathrm{a}$ indicated the content of Z6020-DOPO in CF@Z6020-DOPO was $3.3 \mathrm{wt} \%$, which was close to the calculated value (3.6 $\mathrm{wt} \%)$ according to the statistical data of carbon fabric weights before and after modification. The IR spectra (Figure 5b) of raw CF showed a few weak reflectance peaks, while distinct peaks were observed in the modified CF. The peaks at 770, 1250, and $1455 \mathrm{~cm}^{-1}$ were assigned to $\mathrm{P}-\mathrm{O}-\mathrm{Ph}, \mathrm{P}=\mathrm{O}$, and $\mathrm{P}-\mathrm{Ph}$ groups from the DOPO structure $[28,29]$. The multiple peaks between $1200-900 \mathrm{~cm}^{-1}$ might be assigned to $\mathrm{Si}-\mathrm{O}-\mathrm{Si}$ asymmetric stretching vibrations from the silane structure after the hydrolysis-condensation reactions [30]. To study the bonding environment of $\mathrm{P}$ and $\mathrm{N}$ in the DOPO-based amine functional silane coupling agent, X-ray photoelectron spectroscopy (XPS) measurement was performed. The high-resolution $\mathrm{P} 2 \mathrm{p}$ spectrum (Figure $5 \mathrm{c}$ ) was deconvoluted into three peaks, corresponding to $\mathrm{P}-\mathrm{O}$, $\mathrm{P}-\mathrm{C}$ and $\mathrm{P}-\mathrm{N}$ bonds at $134.2,132.6$, and $133.5 \mathrm{eV}$, respectively [31, 32]. In N 1s spectrum (Figure 5d), the peaks at 401.1,399.3, and $394.9 \mathrm{eV}$ were attributed to $\mathrm{N}-\mathrm{H}, \mathrm{C}-\mathrm{N}$, and $\mathrm{P}-\mathrm{N}$ bonds, respectively [33]. The existence of $\mathrm{P}-\mathrm{N}$ bond proved the AthertonTodd reaction between $\mathrm{P}-\mathrm{H}$ in DOPO and $-\mathrm{NH}_{2}$ in Z-6020. The above SEM images, combined with the EDX, FTIR, TGA, and XPS characterizations, 

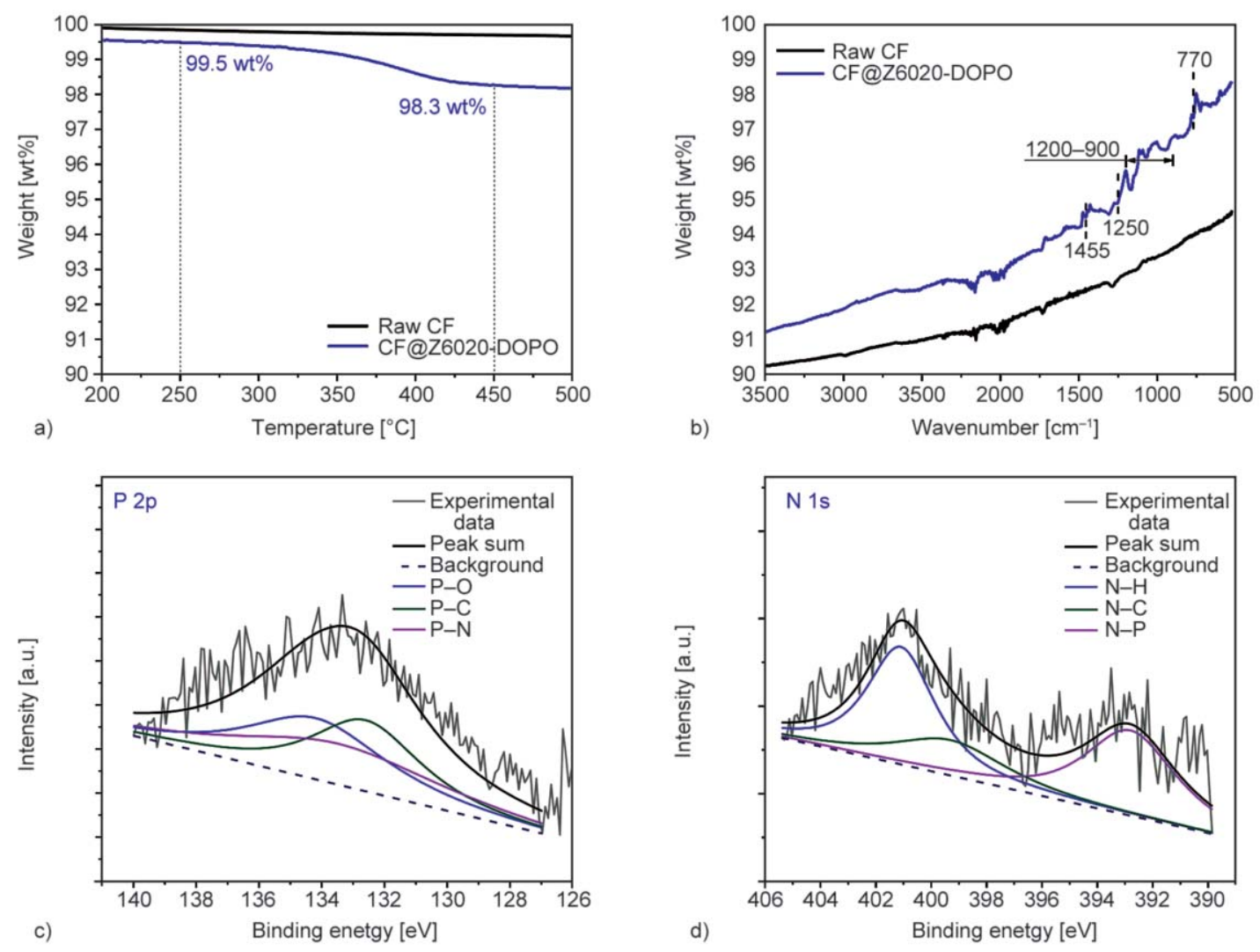

Figure 5. (a) TGA curve and (b) FTIR spectra of raw CF and CF@Z6020-DOPO, the deconvoluted XPS survey of (c) P 2p and (d) N 1s in CF@Z6020-DOPO.

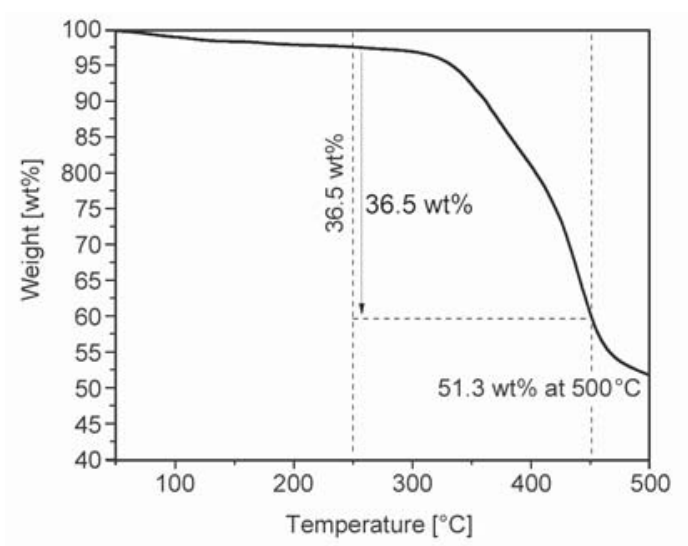

Figure 6. TGA curve of DOPO based silane coupling agent (Z6020-DOPO) under nitrogen atmosphere.

indicated a successful surface modification of raw carbon fabric by the DOPO-based amine functional silane coupling agent (Z6020-DOPO).

\subsection{Fire behavior of $\mathrm{CF} / \mathrm{EP}$ composites}

The flammability of the composites was firstly evaluated by LOI and UL-94 test. The LOI values and UL-94 results of the composites are displayed in Figure 7. The raw CF/EP showed a high LOI value of $28.9 \%$ due to the inherent high thermal resistance of the used EP system (the raw CF/EP composite showed a glass transition temperature of $199^{\circ} \mathrm{C}$ in DMA) and a high weight percentage of non-flammable carbon fabric (the weight percentage of $\mathrm{CF}$ in the composites was calculated to be around 55\%). With the addition of DOPO in the EP matrix, the $\mathrm{CF} / \mathrm{DOPO} / \mathrm{EP}$ showed an increased LOI value of $31.8 \%$. The highest LOI value (33.7\%) was observed in CF@Z6020$\mathrm{DOPO} / \mathrm{EP}$ composite. In the UL-94 test, all the composites displayed a short after-flame time (between 1 to $5 \mathrm{~s}$ ) after the $1 \mathrm{st}$ time ignition. After the $2^{\text {nd }}$ time ignition, both $\mathrm{CF} / \mathrm{EP}$ and $\mathrm{CF} / \mathrm{DOPO} / \mathrm{EP}$ burned till the clamp. On the contrary, CF@Z6020-DOPO showed an average after-flame time of $18 \mathrm{~s}$ after the $2^{\text {nd }}$ time ignition, reaching the $\mathrm{V}-1$ rating. After the LOI test, dense and robust char residues surrounding the surface of the bar specimen were observed for CF@Z6020$\mathrm{DOPO} / \mathrm{EP}$, which are clearly displayed in the insets of Figure 7. The enhanced charring ability greatly contributed to the improved flame retardancy of CF@Z6020-DOPO/EP composite.

A Cone calorimeter test (CCT) was performed to evaluate the heat and smoke release of EP composites under a well-defined fire scenario of forced flaming conditions. Figure 8 displays the heat release rate (HRR) and smoke production rate (SPR) versus time 


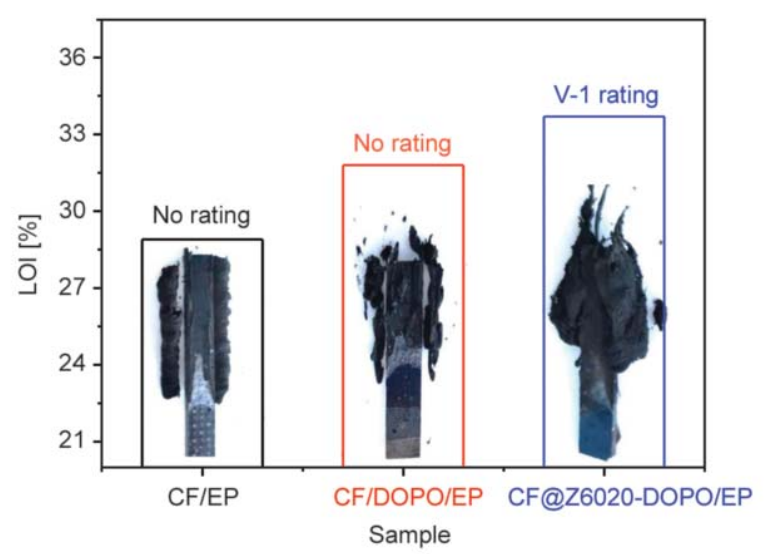

Figure 7. The LOI values and UL-94 ratings of CF/EP composites. The insets are the digital images of specimen bars after LOI tests.

curves of the composite materials. The peak heat release rate (pHRR) of CF/EP was $624 \pm 28 \mathrm{~kW} / \mathrm{m}^{2}$, and it dropped to $463 \pm 21 \mathrm{~kW} / \mathrm{m}^{2}$ for the interfacial mode composite CF@Z6020-DOPO/EP. On the contrary, the bulk mode composite $\mathrm{CF} / \mathrm{DOPO} / \mathrm{EP}$ showed a similar pHRR $\left(623 \pm 41 \mathrm{~kW} / \mathrm{m}^{2}\right)$ with the neat $\mathrm{CF} / \mathrm{EP}$. It is worth noting that CF@Z6020-DOPO/EP displayed a quick drop in heat release rate after the first peak of HRR at $445 \mathrm{~kW} / \mathrm{m}^{2}$. This was mainly due to the burn out of the top-layer epoxy matrix and the build-up of dense char layers within the composite laminate. The second peak of HRR occurred at $45 \mathrm{~s}$ after ignition, which was significantly delayed compared to neat $\mathrm{CF} / \mathrm{EP}$ reaching its $\mathrm{pHRR}$ within $15 \mathrm{~s}$ after ignition. The declined pHRR and prolonged time to $\mathrm{pHRR}$ were beneficial to improve the fire safety of polymer composites. Furthermore, CF@Z6020-DOPO/EP showed a peak smoke production rate of $0.086 \pm 0.008 \mathrm{~m}^{2} / \mathrm{s}$, a $31 \%$ reduction compared to $\mathrm{CF} / \mathrm{EP}\left(0.125 \pm 0.01 \mathrm{~m}^{2} / \mathrm{s}\right)$. The bulk mode composite $\mathrm{CF} / \mathrm{DOPO} / \mathrm{EP}$ showed even more smoke release compared to neat $\mathrm{CF} / \mathrm{EP}$, which is undesired in practical applications. Based on these

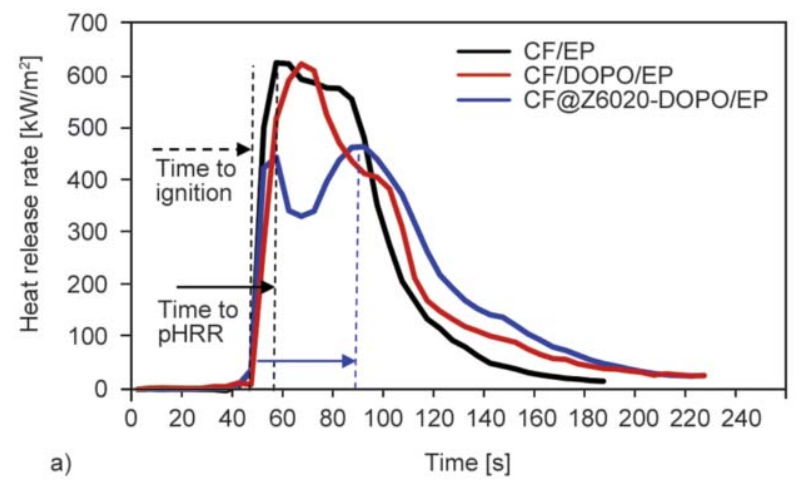

results, we concluded that the flame retardant $\mathrm{CF} / \mathrm{EP}$ composite prepared via the interfacial mode exhibited a superior flame retardancy compared to the bulk mode.

To investigate the flame retardant mechanism, the morphology of specimen residues after CCT was investigated by SEM. The carbon fabric was thermally stable under the combustion conditions and well retained its shape after the test. In terms of CF/EP composite, very smooth and clean carbon fabric was observed after the combustion. Even the middle-layer carbon fabric showed very few char residues, indicating a low charring ability of the pristine EP matrix. As seen from the SEM images in Figure 9a, 9d, very few char residue remained on the fiber surface in $\mathrm{CF} / \mathrm{EP}$, indicating complete combustion of the epoxy matrix. A clearly different morphology was observed for the residue of CF@D6020-DOPO/EP. As shown in Figure 9b, 9e, the surface of the fabric was covered by thick and robust char residues, forming integrated and continuous char layers based on the well-aligned carbon fibers. The intergrowth char residue well filled the gaps between carbon fibers and acted as a perfect barrier to slow down the heat and mass transfer between the flame and underlying polymers, thus effectively reducing the heat release rate of the composite materials. As the control sample, the residue of CF/DOPO/EP (Figure 9c, 9f) showed no continuous morphology and exhibited a weak effect to protect the underlying materials under combustion. These results well explained the high flame retardant efficiency resulting from the intergrowth charring behavior.

The EDX analysis (Figure 10) showed the residue of CF@Z6020-DOPO/EP contained multiple elements, including $\mathrm{C}, \mathrm{O}, \mathrm{Si}, \mathrm{N}$, and $\mathrm{P}$. The atom percentage of $\mathrm{C}, \mathrm{O}, \mathrm{Si}, \mathrm{N}$ and $\mathrm{P}$ was 94.1, 2.6, 2.2, 0.98 and 0.3 , respectively (Figure $10 \mathrm{~b}$ ). Those elements,

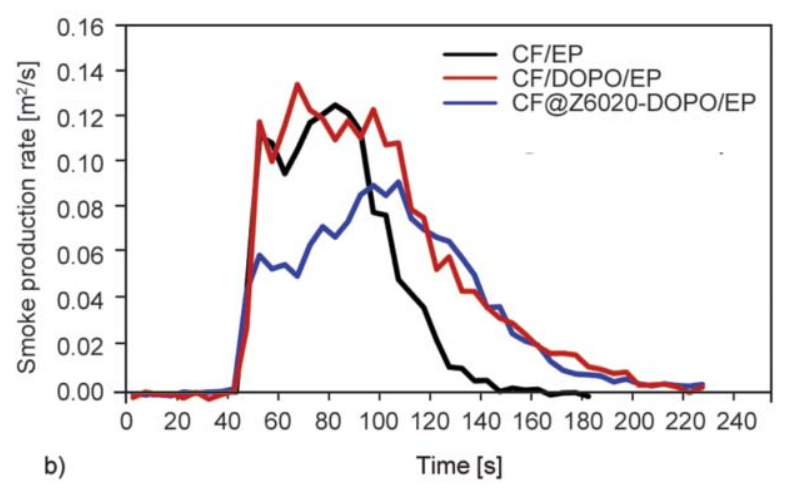

Figure 8. (a) Heat release rate and (b) smoke production rate curves for CF/EP composites. 


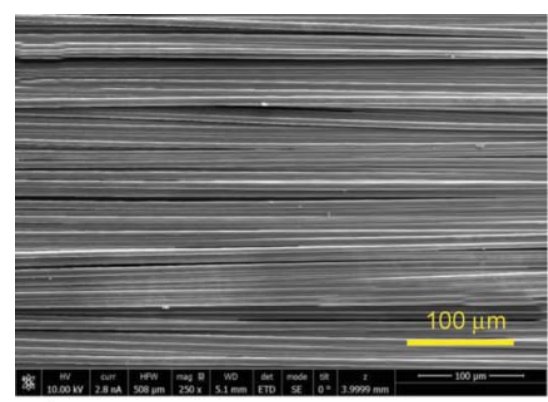

a)

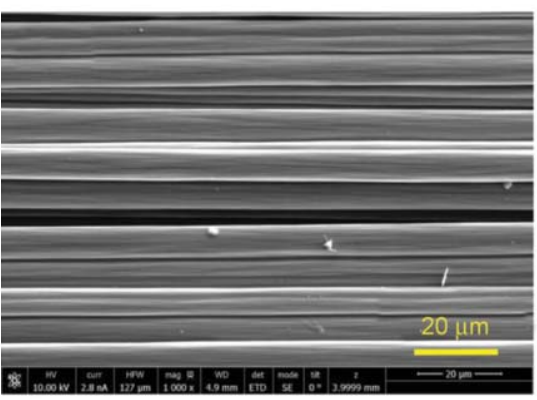

d)

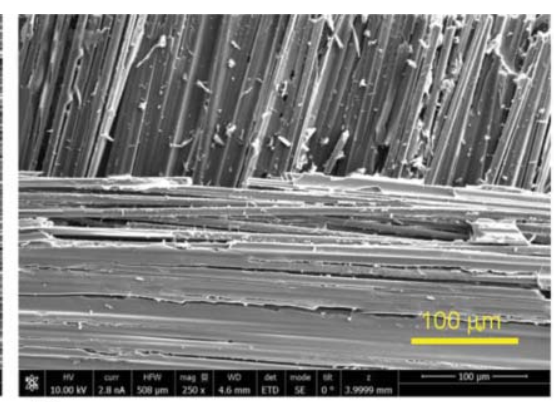

b)

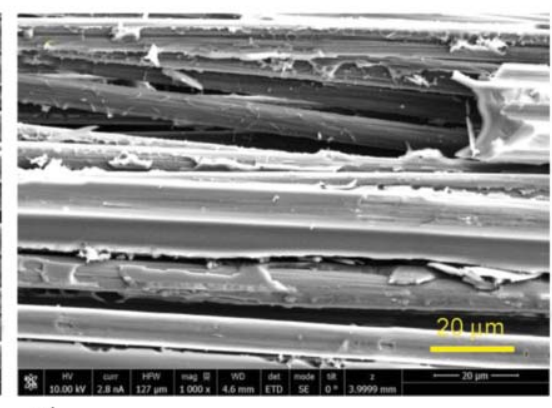

e)

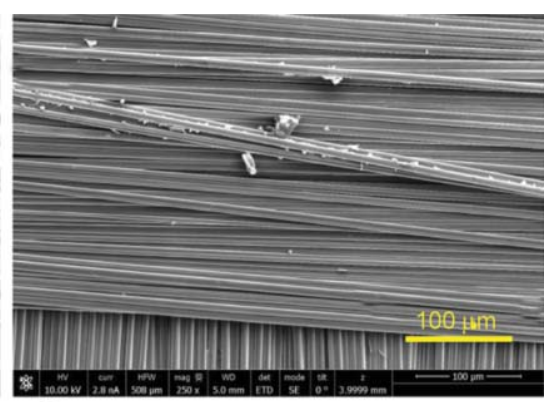

c)

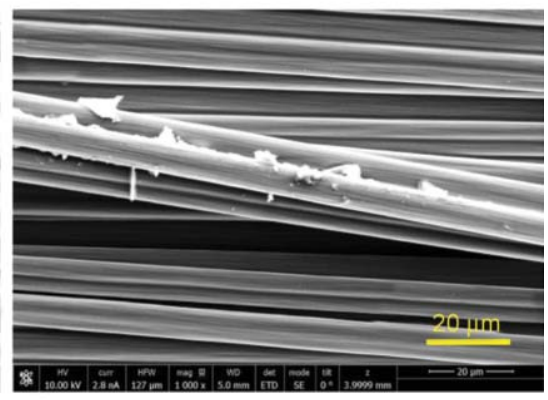

Figure 9. SEM images of char residues after the cone calorimeter test. (a, d) CF/EP; (b, e) CF@Z6020-DOPO/EP; (c, f) $\mathrm{CF} / \mathrm{DOPO} / \mathrm{EP}$

especially $\mathrm{Si} / \mathrm{N} / \mathrm{P}$ well distributed in the residues alongside the carbon fibers (Figure 10c), which proved the good dispersion of flame retardant via the fiber surface modification strategy. Under combustion, the phosphorus-containing silane coupling agent not only showed the catalytic effect to promote the carbonization of the nearby epoxy matrix but also decomposed and acted as the primary residue layer on the fiber surface. The synergistic flame retardant effect among Si/N/P elements proved to be effective in contributing to the intergrowth of carbon residues at the fiber-matrix interface $[34,35]$.

\subsection{Mechanical behavior of CF/EP composites}

The dynamic mechanical analysis was performed to evaluate the mechanical behavior of EP composites. As shown in Figure 11, compared to CF/EP with a storage modulus of $19.2 \mathrm{GPa}$ at $50^{\circ} \mathrm{C}$, an increased storage modulus was observed for CF@Z6020DOPO/EP (20.6 GPa). The increased storage modulus indicated an improved adhesion between carbon fiber and EP matrix [36-38]. On the contrary, the direct mixing of DOPO in the EP matrix severely decreased the storage modulus to $16.5 \mathrm{GPa}$, which was

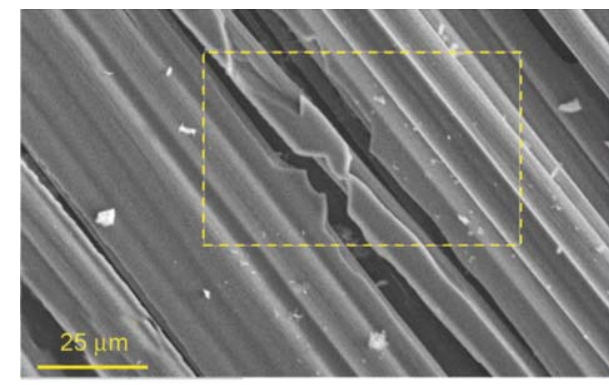

a)

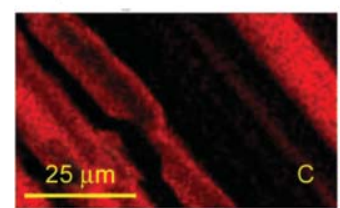

c-i)

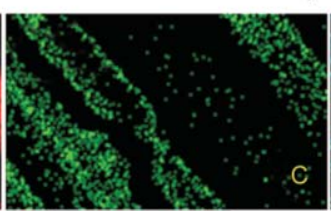

C-ii)

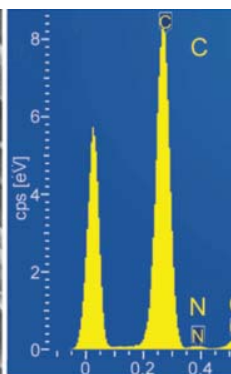

b)

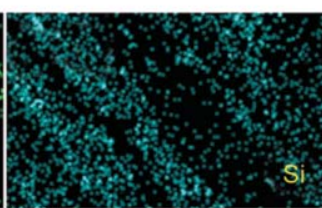

c-iii)

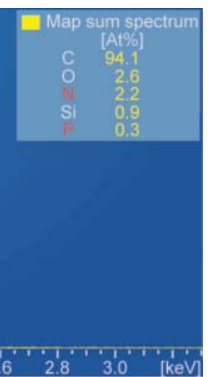

Si $P$

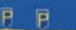

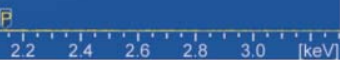

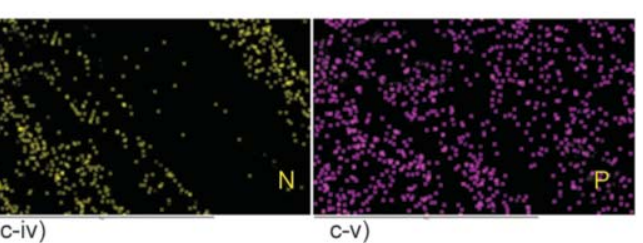

Figure 10. (a) SEM image, (b) EDX spectra and (c) element mappings for char residue of CF@Z6020-DOPO/EP. 

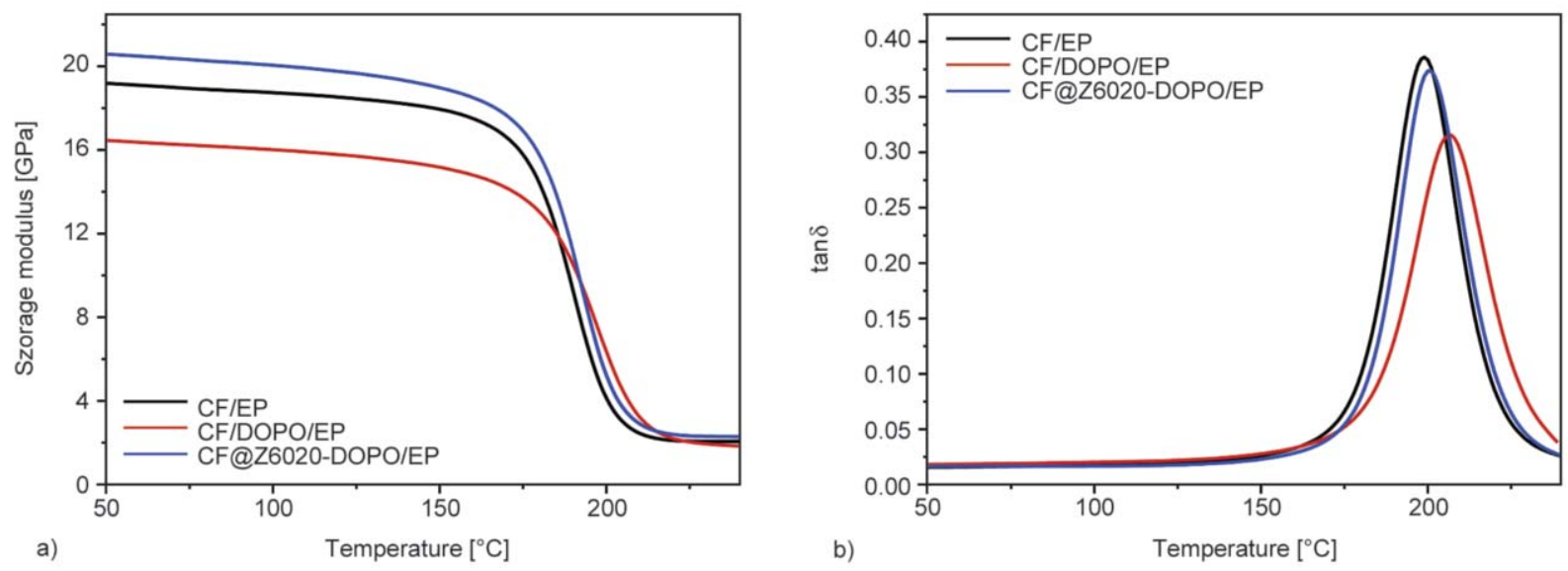

Figure 11. (a) Storage modulus and (b) $\tan \delta$ curves of CF/EP composites.

a $14.1 \%$ decrease compared to CF /EP. It might be due to the existence of phosphorus-containing groups in the bulk epoxy matrix, which had a negative effect on the storage modulus $[39,40]$. The glass transition temperature $\left(T_{\mathrm{g}}\right)$ of raw $\mathrm{CF} / \mathrm{EP}$ was $199^{\circ} \mathrm{C}$, and it increased to $201^{\circ} \mathrm{C}$ for CF@Z6020-DOPO/EP. CF/ $\mathrm{DOPO} / \mathrm{EP}$ showed an increased $T_{\mathrm{g}}\left(207^{\circ} \mathrm{C}\right) \mathrm{com}-$ pared to CF/EP and CF@Z6020-DOPO/EP. During the high temperature $\left(200^{\circ} \mathrm{C}\right)$ post-curing process, DOPO with a reactive $\mathrm{P}-\mathrm{H}$ group and a rigid group of phosphaphenanthrene might incorporate into the backbone of epoxy networks by way of linking to the side chain of epoxy networks [41], which led to a great steric hindrance and thus confine the mobility of molecular chains and improve $T_{\mathrm{g}}$ of cured EP composites [39, 42].

The fiber-matrix interface strength plays a dominant role in the mechanical performance of fiber-reinforced EP composites. To quantitatively evaluate the interface strength, the micro-scope fiber push-in test was adopted. The fiber push-in test was carried out by loading on the center of carbon fiber with a flat-punch indenter until a certain displacement. The applied load $(P)$ and displacement $(u)$ were continuously monitored during the test. The load-displacement curves ( 5 points for each sample) corresponding to CF/EP, CF@Z6020-DOPO/EP, and CF/DOPO/EP were shown in Figure 12. According to the technical data sheet of the carbon fabric, the longitudinal elastic modulus and radius of carbon fiber were set as the constant $240 \mathrm{GPa}$ and $3.5 \mu \mathrm{m}$, respectively. The methodology provided in Ref. [26] was adopted to determine the loading stiffness $\left(S_{0}\right)$ and critical load $\left(P_{\mathrm{c}}\right)$ in each load-displacement curve. Thus, according to Equation (1), the interface shear strength in CF/EP and CF@Z6020-DOPO/EP was calculated to be $11.2 \pm 1.3$ and $15.1 \pm 1.8 \mathrm{MPa}$, respectively. After surface treatment by Z6020-DOPO, an increment of $35 \%$ was observed in the fiber-matrix interfacial shear strength. The improvement was assigned to the strong interaction between EP and amine groups from Z6020 and Z6020-DOPO [43]. The interface shear strength in $\mathrm{CF} / \mathrm{DOPO} / \mathrm{EP}$ was calculated to be $10.9 \pm 1.7 \mathrm{MPa}$, slightly lower than $\mathrm{CF} / \mathrm{EP}$, which contributed to its deceased storage modulus in the DMA test. It's worth noting that a relatively low interface strength value was obtained compared to results in previous literature $[26,44]$, which might be due to the high loading rate $(100 \mathrm{~nm} / \mathrm{s})$ used in this study. To achieve a good mechanical performance in
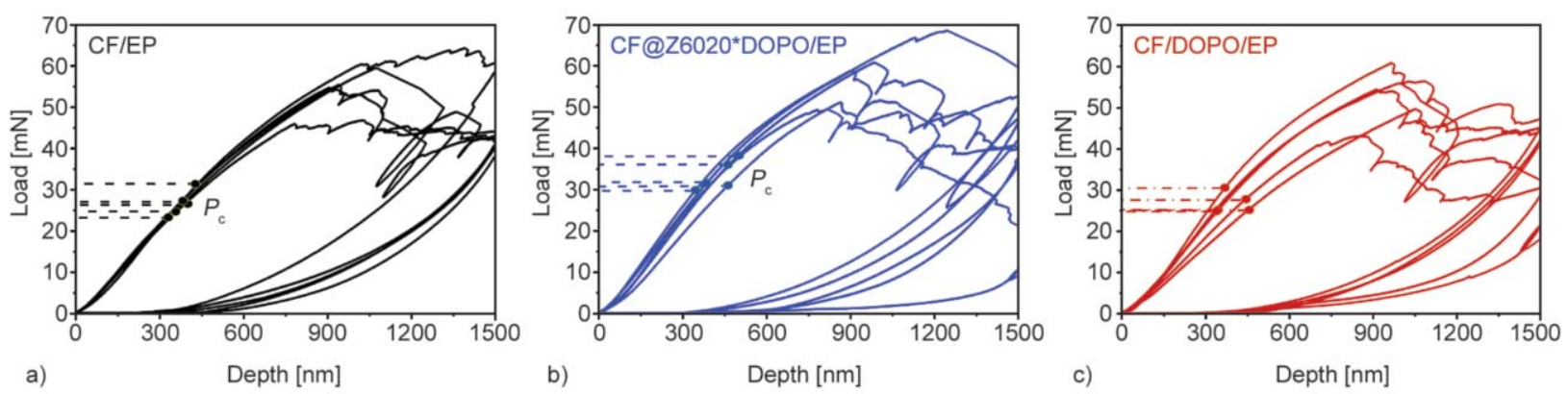

Figure 12. Experimental load-displacement curves in fiber push-in test. (a) CF/EP, (b) CF@Z6020-DOPO/EP, and (c) $\mathrm{CF} / \mathrm{DOPO} / \mathrm{EP}$. 
$\mathrm{CF} / \mathrm{EP}$ composites, the improved fiber-matrix interfacial strength is essential for the efficient stress transfer from the polymer matrix to carbon fibers $[45,46]$. These results provided clear evidence for the increased interfacial strength between modified carbon fiber and EP matrix, which was beneficial to an improved mechanical property of CF@Z6020DOPO/EP composite.

\section{Conclusions}

In this work, the carbon fabric was treated by organophosphorus based amine functional silane coupling agent to enhance the fiber-matrix interfacial strength and the intergrowth charring behavior. Compared to the pristine $\mathrm{CF} / \mathrm{EP}$ composite with high flammability, the resultant flame retardant modified EP composite showed a V-1 rating in the UL-94 test. In addition, the peak heat release rate and smoke release rate of CF@Z6020-DOPO/EP was reduced by $26 \%$ and $31 \%$, respectively. Due to the intergrowth charring behavior, an integrated and dense char layer composed of carbon fabric reinforced intergrowth char residue was formed to protect the polymer materials in the condensed phase. Moreover, the interfacial mode CF/EP composite showed an increased storage modulus, significantly higher than the bulk mode composite. The fiber push-in test clearly revealed an improved fiber-matrix interfacial strength due to the existence of DOPO-based amine functional silane coupling agent. The provided surface functionalization strategy using organophosphorus based amine silane coupling agent proved to be an effective approach to prepare high-performance flame retardant EP composite.

\section{Acknowledgements}

This research is partly funded by the joint Research Fund for Overseas Chinese, Hong Kong, and Macao Young Scholars (51628301) and the financial support from China Scholarship Council (ID: 201506370020) to Mr. Lu Zhang.

\section{References}

[1] He Y., Yang S., Liu H., Shao Q., Chen Q., Lu C., Jiang Y., Liu C., Guo Z.: Reinforced carbon fiber laminates with oriented carbon nanotube epoxy nanocomposites: Magnetic field assisted alignment and cryogenic temperature mechanical properties. Journal of Colloid and Interface Science, 517, 40-51 (2018).

https://doi.org/10.1016/j.jcis.2018.01.087
[2] Zhang X., Fan X., Yan C., Li H., Zhu Y., Li X., Yu L.: Interfacial microstructure and properties of carbon fiber composites modified with graphene oxide. ACS Applied Materials and Interfaces, 4, 1543-1552 (2012). https://doi.org/10.1021/am201757v

[3] Zhang J., Ju S., Jiang D., Peng H-X.: Reducing dispersity of mechanical properties of carbon fiber/epoxy composites by introducing multi-walled carbon nanotubes. Composites Part B: Engineering, 54, 371-376 (2013). https://doi.org/10.1016/j.compositesb.2013.05.046

[4] Kalali E. N., Wang X., Wang D-Y.: Functionalized layered double hydroxide-based epoxy nanocomposites with improved flame retardancy and mechanical properties. Journal of Materials Chemistry A, 3, 6819-6826 (2015).

https://doi.org/10.1039/C5TA00010F

[5] Khalili P., Tshai K. Y., Hui D., Kong I.: Synergistic of ammonium polyphosphate and alumina trihydrate as fire retardants for natural fiber reinforced epoxy composite. Composites Part B: Engineering, 114, 101-110 (2017).

https://doi.org/10.1016/j.compositesb.2017.01.049

[6] Koike T.: Progress in development of epoxy resin systems based on wood biomass in Japan. Polymer Engineering and Science, 52, 701-717 (2012).

https://doi.org/10.1002/pen.23119

[7] Perret B., Schartel B., Stöß K., Ciesielski M., Diederichs J., Döring M., Krämer J., Altstädt V.: A new halogen-free flame retardant based on 9,10-dihydro-9oxa-10-phosphaphenanthrene-10-oxide for epoxy resins and their carbon fiber composites for the automotive and aviation industries. Macromolecular Materials and Engineering, 296, 14-30 (2011).

https://doi.org/10.1002/mame.201000242

[8] Sun F., Yu T., Hu C., Li Y.: Influence of functionalized graphene by grafted phosphorus containing flame retardant on the flammability of carbon fiber/epoxy resin (CF/ER) composite. Composites Science and Technology, 136, 76-84 (2016).

https://doi.org/10.1016/j.compscitech.2016.10.002

[9] Li C., Kang N-J., Labrandero S. D., Wan J., González C., Wang D-Y.: Synergistic effect of carbon nanotube and polyethersulfone on flame retardancy of carbon fiber reinforced epoxy composites. Industrial and Engineering Chemistry Research, 53, 1040-1047 (2014). https://doi.org/10.1021/ie403378w

[10] Zhao X., Zhang L., Alonso J. P., Delgado S., MartínezMiranda M. R., Wang D-Y.: Influence of phenylphosphonic amide on rheological, mechanical and flammable properties of carbon fiber/RTM6 composites. Composites Part B: Engineering, 149, 74-81 (2018). https://doi.org/10.1016/j.compositesb.2018.05.018

[11] Perret B., Schartel B., Stöß K., Ciesielski M., Diederichs J., Döring M., Krämer J., Altstädt V.: Novel DOPO-based flame retardants in high-performance carbon fibre epoxy composites for aviation. European Polymer Journal, 47, 1081-1089 (2011). https://doi.org/10.1016/j.eurpolymj.2011.02.008 
[12] Jiang J., Cheng Y., Liu Y., Wang Q., He Y., Wang B.: Intergrowth charring for flame-retardant glass fabricreinforced epoxy resin composites. Journal of Materials Chemistry A, 3, 4284-4290 (2015).

https://doi.org/10.1039/C4TA06486K

[13] Shi X-H., Chen L., Zhao Q., Long J-W., Li Y-M., Wang Y-Z.: Epoxy resin composites reinforced and fire-retarded by surficially-treated carbon fibers via a tunable and facile process. Composites Science and Technology, 187, 107945/1-107945/7 (2020). https://doi.org/10.1016/j.compscitech.2019.107945

[14] Zhang L., Li Z., Pan Y-T., Yáñez A. P., Hu S., Zhang X-Q., Wang R., Wang D-Y.: Polydopamine induced natural fiber surface functionalization: A way towards flame retardancy of flax/poly(lactic acid) biocomposites. Composites Part B: Engineering, 154, 56-63 (2018). https://doi.org/10.1016/j.compositesb.2018.07.037

[15] Chen W., Liu P., Liu Y., Wang Q.: Interfacial carbonation for efficient flame retardance of glass fiber-reinforced polyamide 6. Polymer Chemistry, 6, 4409-4414 (2015). https://doi.org/10.1039/C5PY00280J

[16] Han Y., Xu Y., Liu Y., Wang Q., Zhang Z., Wang Z.: An efficient interfacial flame-resistance mode to prepare glass fiber reinforced and flame retarded polyamide 6 with high performance. Journal of Materials Chemistry A, 1, 10228-10233 (2013).

https://doi.org/10.1039/c3ta11312d

[17] Totry E., Molina-Aldareguía J. M., González C., LLorca J.: Effect of fiber, matrix and interface properties on the in-plane shear deformation of carbon-fiber reinforced composites. Composites Science and Technology, 70, 970-980 (2010).

https://doi.org/10.1016/j.compscitech.2010.02.014

[18] Lin Y., Ehlert G., Sodano H. A.: Increased interface strength in carbon fiber composites through a $\mathrm{ZnO}$ nanowire interphase. Advanced Functional Materrials, 19, 2654-2660 (2009).

https://doi.org/10.1002/adfm.200900011

[19] Khan S. U., Kim J-K.: Improved interlaminar shear properties of multiscale carbon fiber composites with bucky paper interleaves made from carbon nanofibers. Carbon, 50, 5265-5277 (2012).

https://doi.org/10.1016/j.carbon.2012.07.011

[20] Medina M. C., Molina-Aldareguía J. M., González C., Melendrez M. F., Flores P., LLorca J.: Comparison of push-in and push-out tests for measuring interfacial shear strength in nano-reinforced composite materials. Journal of Composite Materials, 50, 1651-1659 (2016). https://doi.org/10.1177/0021998315595115

[21] Zhang L., Zhang J., Wang D-Y.: Hierarchical layered double hydroxide nanosheets/phosphorus-containing organosilane functionalized hollow glass microsphere towards high performance epoxy composite: Enhanced interfacial adhesion and bottom-up charring behavior. Polymer, 210, 123018/1-123018/10 (2020). https://doi.org/10.1016/j.polymer.2020.123018
[22] Wagner S., Rakotomalala M., Bykov Y., Walter O., Döring M.: Synthesis of new organophosphorus compounds using the atherton-todd reaction as a versatile tool. Heteroatom Chemistry, 23, 216-222 (2012).

https://doi.org/10.1002/hc.21006

[23] Neisius N. M., Lutz M., Rentsch D., Hemberger P., Gaan S.: Synthesis of DOPO-based phosphonamidates and their thermal properties. Industrial and Engineering Chemistry Research, 53, 2889-2896 (2014). https://doi.org/10.1021/ie403677k

[24] Ou Y., González C., Vilatela J. J.: Interlaminar toughening in structural carbon fiber/epoxy composites interleaved with carbon nanotube veils. Composites Part A: Applied Science and Manufacturing, 124, 105477/1105477/11 (2019).

https://doi.org/10.1016/j.compositesa.2019.105477

[25] Kharrat M., Chateauminois A., Carpentier L., Kapsa P.: On the interfacial behaviour of a glass/epoxy composite during a micro-indentation test: Assessment of interfacial shear strength using reduced indentation curves. Composites Part A: Applied Science and Manufacturing, 28, 39-46 (1997). https://doi.org/10.1016/S1359-835X(96)00092-9

[26] Rodríguez M., Molina-Aldareguía J. M., González C., LLorca J.: A methodology to measure the interface shear strength by means of the fiber push-in test. Composites Science and Technology, 72, 1924-1932 (2012). https://doi.org/10.1016/j.compscitech.2012.08.011

[27] Zidi M., Carpentier L., Chateauminois A., Sidoroff F.: Quantitative analysis of the micro-indentation behaviour of fibre-reinforced composites: Development and validation of an analytical model. Composites Science and Technology, 60, 429-437 (2000). https://doi.org/10.1016/S0266-3538(99)00143-8

[28] Zhang Z., Yuan L., Liang G., Gu A., Qiang Z., Yang C., Chen X.: Unique hybridized carbon nanotubes and their high performance flame retarding composites with high smoke suppression, good toughness and low curing temperature. Journal of Materials Chemistry A, 2, 49754988 (2014).

https://doi.org/10.1039/C3TA14687A

[29] Liu B., Gao X., Zhao Y., Dai L., Xie Z., Zhang Z.: 9,10dihydro-9-oxa-10-phosphaphenanthrene 10-oxide-based oligosiloxane as a promising damping additive for methyl vinyl silicone rubber (VMQ). Journal of Materials Science, 52, 8603-8617 (2017).

https://doi.org/10.1007/s10853-017-1085-7

[30] Shao G., Wu X., Kong Y., Cui S., Shen X., Jiao C., Jiao J.: Thermal shock behavior and infrared radiation property of integrative insulations consisting of $\mathrm{MoSi}_{2} /$ borosilicate glass coating and fibrous $\mathrm{ZrO}_{2}$ ceramic substrate. Surface and Coatings Technology, 270, 154-163 (2015).

https://doi.org/10.1016/j.surfcoat.2015.03.008 
[31] Wu J., Zheng X., Jin C., Tian J., Yang R.: Ternary doping of phosphorus, nitrogen, and sulfur into porous carbon for enhancing electrocatalytic oxygen reduction. Carbon, 92, 327-338 (2015).

https://doi.org/10.1016/j.carbon.2015.05.013

[32] Wang C., Sun L., Zhou Y., Wan P., Zhang X., Qiu J.: $\mathrm{P} / \mathrm{N}$ co-doped microporous carbons from $\mathrm{H}_{3} \mathrm{PO}_{4}$-doped polyaniline by in situ activation for supercapacitors. Carbon, 59, 537-546 (2013).

https://doi.org/10.1016/j.carbon.2013.03.052

[33] Wang J., Hu Y., Cai W., Yuan B., Zhang Y., Guo W., Hu W., Song L.: Atherton-Todd reaction assisted synthesis of functionalized multicomponent $\mathrm{MoSe}_{2} / \mathrm{CNTs}$ nanoarchitecture towards the fire safety enhancement of polymer. Composites Part A: Applied Science and Manufacturing, 112, 271-282 (2018).

https://doi.org/10.1016/j.compositesa.2018.06.013

[34] Qi Z., Zhang W., He X., Yang R.: High-efficiency flame retardency of epoxy resin composites with perfect $\mathrm{T} 8$ caged phosphorus containing polyhedral oligomeric silsesquioxanes (P-POSSs). Composites Science and Technology, 127, 8-19 (2016).

https://doi.org/10.1016/j.compscitech.2016.02.026

[35] Zhang W., Li X., Fan H., Yang R.: Study on mechanism of phosphorus-silicon synergistic flame retardancy on epoxy resins. Polymer Degradation and Stability, 97, 2241-2248 (2012).

https://doi.org/10.1016/j.polymdegradstab.2012.08.002

[36] Rittigstein P., Priestley R. D., Broadbelt L. J., Torkelson J. M.: Model polymer nanocomposites provide an understanding of confinement effects in real nanocomposites. Nature Materials, 6, 278-282 (2007).

https://doi.org/10.1038/nmat1870

[37] John M. J., Anandjiwala R. D.: Chemical modification of flax reinforced polypropylene composites. Composites Part A: Applied Science and Manufacturing, 40, 442-448 (2009). https://doi.org/10.1016/j.compositesa.2009.01.007

[38] Vilay V., Mariatti M., Mat Taib R., Todo M.: Effect of fiber surface treatment and fiber loading on the properties of bagasse fiber-reinforced unsaturated polyester composites. Composites Science and Technology, 68, 631-638 (2008).

https://doi.org/10.1016/j.compscitech.2007.10.005
[39] Ciesielski M., Schäfer A., Döring M.: Novel efficient DOPO-based flame-retardants for PWB relevant epoxy resins with high glass transition temperatures. Polymers for Advanced Technologies 19, 507-515 (2008). https://doi.org/10.1002/pat.1090

[40] Wang X., Hu Y., Song L., Yang H., Xing W., Lu H.: Synthesis and characterization of a DOPO-substitued organophosphorus oligomer and its application in flame retardant epoxy resins. Progress in Organic Coatings, 71, 72-82 (2011). https://doi.org/10.1016/j.porgcoat.2010.12.013

[41] Wang Y., Yuan Y., Zhao Y., Liu S., Zhao J.: Flame-retarded epoxy resin with high glass transition temperature cured by DOPO-containing H-benzimidazole. High Performance Polymers, 29, 94-103 (2017). https://doi.org/10.1177/0954008316628967

[42] Sun J., Wang X., Wu D.: Novel spirocyclic phosphazene-based epoxy resin for halogen-free fire resistance: Synthesis, curing behaviors, and flammability characteristics. ACS Applied Materials and Interfaces, 4, 4047-4061 (2012). https://doi.org/10.1021/am300843c

[43] Lee C. Y., Bae J-H., Kim T-Y., Chang S-H., Kim S. Y.: Using silane-functionalized graphene oxides for enhancing the interfacial bonding strength of carbon/ epoxy composites. Composites Part A: Applied Science and Manufacturing, 75, 11-17 (2015).

https://doi.org/10.1016/j.compositesa.2015.04.013

[44] Hobbiebrunken T., Hojo M., Adachi T., De Jong C., Fiedler B.: Evaluation of interfacial strength in CF/epoxies using FEM and in-situ experiments. Composites Part A: Applied Science and Manufacturing, 37, 22482256 (2006).

https://doi.org/10.1016/j.compositesa.2005.12.021

[45] Totry E., Molina-Aldareguía J. M., González C., LLorca J.: Effect of fiber, matrix and interface properties on the in-plane shear deformation of carbon-fiber reinforced composites. Composites Science and Technology, 70, 970-980 (2010).

https://doi.org/10.1016/j.compscitech.2010.02.014

[46] Demir B., Henderson L. C., Walsh T. R.: Design rules for enhanced interfacial shear response in functionalized carbon fiber epoxy composites. ACS Applied Materials and Interfaces, 9, 11846-11857 (2017). https://doi.org/10.1021/acsami.6b16041 